\title{
Glycemic Control, Diabetes Complications and Their Determinants Among Ambulatory Diabetes Mellitus Patients in Southwest Ethiopia: A Prospective Cross-Sectional Study
}

This article was published in the following Dove Press journal:

Diabetes, Metabolic Syndrome and Obesity: Targets and Therapy

\author{
Mohammed YimamAhmed' \\ Solomon Hambisa Ejigu ${ }^{2}$ \\ Ameha Zewudie Zeleke $\mathbb{D}^{2}$ \\ Mohammed Yimam Hassen ${ }^{2}$ \\ 'Dubti General Hospital, Dubti, Afar \\ Region, Ethiopia; ${ }^{2}$ Department of \\ Pharmacy, College of Health Sciences, \\ Mizan-Tepi University, Mizan-Aman, \\ Ethiopia
}

Background: Over the past two decades, the prevalence of diabetes has increased faster in low- and middle-income countries than in high-income countries. Regardless of the instant growth in the prevalence of diabetes in Ethiopia, up-to-date data regarding glycemic control and related complications of diabetes is inadequate. This study aimed to identify glycemic control and chronic complications and their determinants among ambulatory diabetic patients at Mizan-Tepi University Teaching Hospital (MTUTH).

Methods: We conducted facility-based cross-sectional study from February 25 to March 25, 2019, at Mizan-Tepi University Teaching Hospital. Patients' demographic data, diabetes complications, and treatments were collected using pretested questionnaire and data abstraction format. Data was entered by using Epidata manager 4.0.2.101, and statistical analysis was done by SPSS version 21. Bivariate logistic regression was done to see the association between independent variables and glycemic control and complication. Multivariable logistic regression analyses using backward selection were done to identify the predictors of poor glycemic control and complication at a $P$-value of $<0.05$.

Results: One hundred ambulatory diabetic patients were included in this study. The mean duration of diabetes and the mean age of the participants were $3.95 \pm 5.85$ and $46.66 \pm 15.53$ years, respectively. About 71 (71\%) of the studied diabetic patients had uncontrolled fasting blood glucose (FBG) level. More than half of the diabetic patients $(59 \%)$ developed chronic complications of diabetes. Low medication adherence (adjusted odds ratio $(A O R)=11.78$, 95\%CI: 1.09-17.17) and inappropriate doses in the first, second, and third clinic visits $(\mathrm{AOR}=7.70,95 \% \mathrm{CI}: 1.79-33.01 ; \mathrm{AOR}=8.09,95 \% \mathrm{CI}: 1.90-34.33 ; \mathrm{AOR}=4.34,95 \% \mathrm{CI}$ : 1 .09-17.17), respectively, were independent predictors of uncontrolled FBG. No variable was found to be an independent predictor of chronic diabetic complication on multivariable logistic regression analyses.

Conclusion: Poor glycemic control and diabetes complications among ambulatory diabetic patients were high. Low medication adherence and inappropriate doses in the first, second, and third clinic visits were independent predictors of poor glycemic control.

Keywords: diabetes, glycemic control, complications, Ethiopia

\section{Introduction}

Diabetes mellitus (DM) is a group of metabolic disorders characterized by hyperglycemia resulting from absolute insulin deficiency, relative insulin deficiency, and/or peripheral insulin resistance. Untreated and long-term hyperglycemia secondary to DM
Correspondence: Mohammed Yimam Hassen

Email mohammedimam0094@gmail.com 
may irreversibly damage vital organ and results in retinopathy, nephropathy, neuropathy, and failure of other organs like heart and blood vessels. ${ }^{1}$ The overall global prevalence of DM is $8.8 \%$. This infers that approximately 415 million people are living with diabetes. If this drift continues without any mediation, the number of diabetic patients is estimated to escalate to 642 million by 2040. Estimates by the International Diabetes Federation (IDF) propose about 29.3 million diabetic patients live on the continent of Africa. The projected global expenditure due to diabetes is about 673 billion dollars, of which, nearly $80 \%$ was attributed to rich countries while merely $20 \%$ was attributed to poor countries. ${ }^{2} \mathrm{DM}$ prevalence has risen faster in low- and middle-income countries than in high income countries over the last 10 years. ${ }^{3}$ Most of the diabetic patients are unaware that they have the disorder and the rate of undiagnosed DM is relatively high in sub-Saharan countries, so that the patients are high risk of developing chronic diabeticcomplications. In addition to the current challenges of resource limitation, poor countries face a double burden from both communicable and noncommunicable diseases and associated risks. ${ }^{4}$ Studies reported that $>60 \%$ of patients with diabetes had poor glycemic control despite strict adherence to clinical practice guidelines. ${ }^{5}$ Likewise, a study done in primary health clinics of Malaysia shown that hemoglobin A1C (HbAlc) levels was not achieved among diabetic patients. Drug utilization pattern, age, drug adherence, and duration of diabetes were factors that influenced the outcome of glycemic control. ${ }^{6}$ Moreover, the study conducted at Jimma University Medical Center (JUMC) showed that a substantial number of diabetic patients did not achieve the glycemic target. Antidiabetic treatment, educational status, occupation, and drug adherence of the patients were factors affecting glycemic control. ${ }^{7}$ Any types of long-term hyperglycemia due to DM may result in permanent organ damage in many parts of the body and it can intensify the premature risk of dying. The potential long-term complication of DM includes renal failure, stroke, heart attack, amputation of lower extremities, loss of vision, and nerve damage. ${ }^{3}$ These chronic complications are two to fivefold more prevalent among patients with diabetes. ${ }^{8}$ The study done in Addis Ababa at Minilik II hospital indicated that about $37.5 \%$ of diabetic patients had chronic complications. Peripheral neuropathy and retinopathy were the two most commonly diagnosed chronic complications of DM and attributed $35.2 \%$ and $31.4 \%$ of the cases, respectively. ${ }^{9}$ The study carried out at JUMC indicated that types of DM, duration of diabetes, age and sex of the patients significantly affects the development of long-term diabetic complications. ${ }^{10}$ Even though the prevalence of vision-threatening retinopathy is $7 \%$, studies indicated that the prevalence of overall retinopathy is $35 \%$. Diabetic patients with low socioeconomic status, type 1 diabetic patients, and those with longer duration of diabetes were associated with high prevalence of retinopathy. Adult diabetic patients are two to three times more likely to have cardiovascular diseases (CVD) than adults devoid of DM. ${ }^{3}$ Chronic diabetes complications can be delayed or prevented by controlling blood pressure, blood glucose and blood cholesterol to the normal level or as close as possible to the normal level. ${ }^{2}$ Studies have showed that poor glycemic control was associated with both micro and macro vascular complications. ${ }^{11}$ Among sub-Saharan African Countries, Ethiopia is in the top four countries where the prevalence of DM mellitus is relatively high. The rates of attendances and diabetic admissions in major hospitals have increased over the past two decades. ${ }^{12}$ In Ethiopia, the prevalence of DM has escalated and is becoming the major economic problem in medical admissions and drug expenditure. ${ }^{13}$ Regardless of the instant growth of the prevalence of DM in Ethiopia, up-to-date data regarding glycemic control and related complications of diabetes is inadequate. Moreover, there is conflicting data with regard to factors affecting glycemic control and no research was done on diabetic complications and its determinants in Southwest Ethiopia. Hence, the aim of this study was to explore the level of glycemic control, chronic complications of diabetes and their determinants in resource constrained setting.

\section{Patients and Methods Study Setting and Study Design}

The study was done in MTUTH in Benchi-Shako Zone, South-west Ethiopia. The hospital has an outpatient service where ambulatory diabetic patients have a regular follow-up every month and sometimes every three months. A facilitybased cross-sectional study was conducted prospectively at MTUTH from February 25 to March 25, 2019.

We received ethical clearance from Mizan-Tepi University Ethical review board and letter of permission was received from the chief executive officer of the hospital to access patients' data. The ethical consideration involved Helsinki declaration statement of ethical principles for medical research involving human subjects. Accordingly, written informed consent was obtained from each study participant prior to data collection and the participants' right to withdraw at any time of the interview was maintained. Similarly, 
generated scientific information does not pose any risk to the study participants. Patient charts were also handled properly and data was kept confidential and anonymous.

\section{Patient Population}

We undertook our study on 100 diabetic patients. The source populations were all adult diabetic patients who had regular follow-up at MTUTH while the study populations were all adult diabetic patients who attended diabetic clinics during study period and fulfill inclusion criteria. Diabetic patients with age $\geq 18$ years, patients who were on antidiabetic medication and with at least three consecutive blood glucose measurements were included in our study. We excluded patients not willing to give written informed consent, patients who had active psychiatric diseases, and those patients who had incomplete medical records.

\section{Data Collection and Outcome of the Study}

The main outcomes of our study were glycemic control and chronic diabetes complications. Data abstraction format was used to extract relevant patient data on duration of illness, type of antidiabetic medication, type of diabetes, medication dose, blood glucose measurement, comorbid conditions, and chronic diabetes complications. We used a semi-structured questionnaire to collect patients' sociodemographic data and medication adherence. Morisky Medication Adherence Scale (MMAS-8) for chronic diseases ${ }^{14}$ was utilized to collect information regarding patient's medication adherence. MMAS is and eight-item questionnaire with dichotomous responses (yes/no) for the first seven questions and multiple choice for the last question. A numerical value of 1 was given for yes and 0 for no. If the patient answered never or rarely for the last question it was scored as 0 or 1 and if the patient replied other choices it was scored as 1 . Adherence level was measured by taking the summation of the response of eight questions and categorized as high, medium or low, if the total score was 0,1 to 2 and $\geq 3$ respectively.

\section{Statistical Analysis}

Data was entered by using EpiData manager 4.0.2.101 (EpiData Association, Denmark) and statistical analysis was done by SPSS version 21 (IBM Corporation, Armonk, NY, USA). Bivariate logistic regression was done to see the association between independent variables and glycemic control and complications. Variables with $P$-value $\leq 0.25$ on bivariate logistic regression were entered into multivariate logistic regression. Multivariable logistic regression analyses using backward selection were done to identify predictors of poor glycemic control and complications at $P$-value of $<0.05$ significant.

\section{Operational Definitions and Definition of Terms Comorbidity}

The presence of other chronic diseases in addition to diabetic mellitus.

\section{Fasting Blood Glucose}

Blood glucose measured from venous blood after at least eight hours of overnight fasting.

\section{Good Glycemic Control}

Operationalized as if the patients had $70-130 \mathrm{mg} / \mathrm{dL}$ of fasting blood glucose (FBG) upon measurement of three consecutive visits.

\section{Poor Glycemic Control}

Operationalized as if the patients had $>130$ or $<70 \mathrm{mg} / \mathrm{dL}$ of FBG upon measurement of three consecutive visits.

\section{Results}

\section{Characteristics of Participants}

Among 105 diabetic patients available during the study period, 100 of them fulfilled the inclusion criteria and were included in the study. The mean age of participants was $46.66 \pm 15.35$ with range of 11-76 years. Fifty-eight $(58 \%)$ of them were male. More than half $(51 \%)$ of the patients had attended secondary school and about one third of them (34\%) were government employees (Table 1).

\section{Clinical Characteristics of the Participants}

Out of the entire 100 studied diabetic patients, 71 (71\%) had poor glycemic control. The mean of FBG measured over three months was $158.75 \pm 47.61 \mathrm{mg} / \mathrm{dL}$. The majority, $76(76 \%)$, of the participants were type 2 diabetic patients. The mean duration of diabetes was $3.95 \pm 5.85$ years. Approximately fewer than half of the patients (46\%) were on antidiabetic medications for two to five years. Forty $(40 \%)$ patients had at least one comorbidity, of which hypertension accounted $82.5 \%$ of total comorbidity. A majority, (59\%) of the participants had developed chronic complications of diabetes. The most common chronic diabetes complication was peripheral neuropathy and accounted $69.5 \%$ of the cases (Table 2). 
Table I Sociodemographic Characteristics of Ambulatory Diabetic Patients at MTUTH, February 25 to March 25, 2019

\begin{tabular}{|c|c|c|}
\hline Variables & Variable Category & Frequency (\%) \\
\hline \multirow[t]{2}{*}{ Sex } & Male & $58(58)$ \\
\hline & Female & $42(42)$ \\
\hline \multirow[t]{4}{*}{ Age category } & $<30$ & $16(16)$ \\
\hline & $30-44$ & $16(16)$ \\
\hline & $45-64$ & $56(56)$ \\
\hline & $\geq 65$ & $12(12)$ \\
\hline \multirow[t]{3}{*}{ Religion } & Muslim & $29(29)$ \\
\hline & Orthodox & $57(57)$ \\
\hline & Protestant & $14(14)$ \\
\hline \multirow[t]{5}{*}{ Ethnicity } & Amhara & $47(47)$ \\
\hline & Bench & $\mathrm{II}(\mathrm{II})$ \\
\hline & Kaffa & $19(19)$ \\
\hline & Oromo & $13(13)$ \\
\hline & Other ${ }^{\mathrm{a}}$ & $10(10)$ \\
\hline \multirow[t]{3}{*}{ Marital status } & Single & $10(10)$ \\
\hline & Married & $84(84)$ \\
\hline & Other $^{b}$ & $6(6)$ \\
\hline \multirow[t]{6}{*}{ Occupation } & Unemployment & $27(27)$ \\
\hline & Governmental employee & $32(32)$ \\
\hline & Private employee & $9(9)$ \\
\hline & Farmer & $12(12)$ \\
\hline & Merchant & $16(16)$ \\
\hline & Other $^{c}$ & $4(4)$ \\
\hline \multirow[t]{4}{*}{ Educational status } & Illiterate & $4(4)$ \\
\hline & Primary education & $29(29)$ \\
\hline & Secondary education & $5 I(5 I)$ \\
\hline & College and above & $16(16)$ \\
\hline
\end{tabular}

Note: ${ }^{\mathrm{a} G u r a g e, ~ S i l t e, ~ Y e m ~ a n d ~ T i g r e ; ~}{ }^{\mathrm{b}}$ widowed and divorced; ${ }^{\mathrm{c}}$ mechanic and driver.

\section{Medication-related Factors}

Twenty-nine (29\%) of the participants were prescribed with insulin while metformin was prescribed for $27 \%$ of them. More than third (36\%) of diabetic patients were taking the combination of glibenclamide and metformin. Fifty-nine (59\%) diabetic patients were on monotherapy. Concerning the antidiabetic medications dose appropriateness in the last three clinic visits, nearly in two-thirds of the patients (63\%) it was incorrect. Around half (48\%) of the patients had medium level of medication adherence (Table 3).

\section{Predictors of Poor Glycemic Control}

On multivariate logistic regression analysis, low adherence to medication ( $\mathrm{AOR}=11.78,95 \% \mathrm{CI}$ : 1.09-17.17), inappropriate doses during the first clinic visit $(\mathrm{AOR})=7.70$,
Table 2 Disease-related Characteristics of Ambulatory Diabetic Patients at MTUTH, February 25 to March 25, 2019

\begin{tabular}{|c|c|c|}
\hline Variable Category & & $\begin{array}{l}\text { Frequency } \\
\text { (\%) }\end{array}$ \\
\hline $\begin{array}{l}\text { Level of glycemic } \\
\text { control }\end{array}$ & $\begin{array}{l}\text { Good } \\
\text { Poor }\end{array}$ & $\begin{array}{l}71(7 I) \\
29(29)\end{array}$ \\
\hline Type of diabetes & $\begin{array}{l}\text { Type I diabetes } \\
\text { Type } 2 \text { diabetes }\end{array}$ & $\begin{array}{l}24(24) \\
76(76)\end{array}$ \\
\hline $\begin{array}{l}\text { Duration of diabetes } \\
\text { (years) }\end{array}$ & $\begin{array}{l}\leq 1 \\
2-5 \\
>5\end{array}$ & $\begin{array}{l}32(32) \\
46(46) \\
22(22)\end{array}$ \\
\hline Comorbidity & $\begin{array}{l}\text { Yes } \\
\text { No }\end{array}$ & $\begin{array}{l}40(40) \\
60(60)\end{array}$ \\
\hline Type of comorbidity & $\begin{array}{l}\text { Hypertension } \\
\text { Asthma } \\
\text { Hypertension plus Asthma } \\
\text { Peptic ulcer disease }\end{array}$ & $\begin{array}{l}30(30) \\
2(2) \\
3(3) \\
5(5)\end{array}$ \\
\hline Complication & $\begin{array}{l}\text { Yes } \\
\text { No }\end{array}$ & $\begin{array}{l}59(59) \\
4 I(4 I)\end{array}$ \\
\hline $\begin{array}{l}\text { Types of } \\
\text { complications }\end{array}$ & $\begin{array}{l}\text { Peripheral neuropathy only } \\
\text { Impotency only } \\
\text { Retinopathy } \\
\text { Diabetic foot ulcer } \\
\text { Peripheral neuropathy + } \\
\text { retinopathy } \\
\text { Peripheral neuropathy + } \\
\text { impotency }\end{array}$ & $\begin{array}{l}41(69.5) \\
5(8.5) \\
5(8.5) \\
4(6.8) \\
3(5.1) \\
1(1.7)\end{array}$ \\
\hline
\end{tabular}

95\%CI: 1.79-33.01), inappropriate doses during second clinic visit (AOR $=8.09,95 \% \mathrm{CI}: 1.90-34.33$ ) and inappropriate doses during third clinic visits $(\mathrm{AOR}=4.34,95 \% \mathrm{CI}$ : 1 .09-17.17) were independent risk factors of poor glycemic control among participants (Table 4).

\section{Predictors of Complications}

Even if numerous variables were associated with diabetic complications on univariate analysis, no variable was found to be an independent predictor of complications on multivariable analysis (Table 5).

\section{Discussion}

This study set out the level of glycemic control and diabetes-related complications. Moreover, we have assessed the factors associated with poor glycemic control and diabetes-related chronic complications. Our study showed that the majority $(71 \%)$ of patients had poorly controlled DM. The mean FBG was $158.75 \pm 47.61 \mathrm{mg} / \mathrm{dL}$. This result 
Table 3 Medication-related Characteristics of Ambulatory Diabetic Patients at MTUTH, February 25 to March 25, 2019

\begin{tabular}{|l|l|l|}
\hline Variable Category & & $\begin{array}{l}\text { Frequency } \\
\text { (\%) }\end{array}$ \\
\hline $\begin{array}{l}\text { Type of antidiabetic } \\
\text { medications }\end{array}$ & $\begin{array}{l}\text { Insulin } \\
\text { Metformin } \\
\text { Glibenclamide }\end{array}$ & $\begin{array}{l}29(29) \\
27(27) \\
3(3)\end{array}$ \\
& Metformin + & $36(36)$ \\
glibenclamide & \\
Insulin + & $5(5)$ \\
\hline First clinic visit dosage & metformin & \\
appropriateness & Inappropriate dose & $70(70)$ \\
Second clinic visit dosage & Correct dose & $30(30)$ \\
appropriateness & Inappropriate dose & $60(60)$ \\
Third clinic visit dosage & Correct dose & $40(40)$ \\
appropriateness & Inappropriate dose & $59(59)$ \\
\hline Medication adherence level & Correct dose & $41(41)$ \\
\hline & High & $9(9)$ \\
& Medium & $48(48)$ \\
& Low & $43(43)$ \\
\hline
\end{tabular}

is comparable with the study done at Jimma University Teaching Hospital ${ }^{7}$ where $70.9 \%$ of patients had poorly controlled diabetes. Our finding is higher than the Iranian study $^{15}$ in which $56.3 \%$ of diabetic patients had poorly controlled diabetes and the findings of University of Gondar Hospital, Ethiopia ${ }^{16}$ where $60.5 \%$ of patients had poor glycemic control. This difference might be due to variations in the study settings, urbanization, the method of glucose measurement and study populations. For instance, in the Iranian study, all the participants were female diabetic patients.
Conversely, our result is lower than the findings in India $^{11}$ and Kenya ${ }^{17}$ in which uncontrolled DM presented in $78.6 \%$ and $81.6 \%$ of diabetic patients. This discrepancy might be due to inconsistencies in the way of investigating blood glucose levels. HbA1C was used as assessment tool for glycemic control in former studies whereas FBG was used to assess glycemic control in present study.

Low level of medication adherence and inappropriate dose in the first, second, and third clinic visits were independent predictors of poorly controlled DM. This study showed that low level of adherence to the prescribed antidiabetic medications has a deleterious impact on glycemic control. The finding of this study was consistent with findings in research done in Malaysia, ${ }^{6}$ which indicated that glycemic control was higher among patients who adhered to their antidiabetic medications. This can be elucidated since effectiveness of drug treatment depends principally on the efficacy of the prescribed medication and adherence of the patient to the treatment. In our study, individuals taking inappropriate doses of antidiabetic medications were more likely to have uncontrolled DM compared to their counterparts.

Our study found that $59 \%$ of study participants had diabetes-related complications. This finding is considerably higher when compared to those from Minilik II hospital, Ethiopia ${ }^{9}$ where $37.45 \%$ of diabetic patients had one or more chronic complications of diabetes. Moreover, the finding of the present study is higher than that from the University of Gondar Hospital, Ethiopia ${ }^{16}$ in which chronic diabetes complications were found in $31.33 \%$ of diabetic patients. The variation in the sample size and level of care given to diabetes patients might have contributed

Table 4 Predictors of Poor Glycemic Control Among Ambulatory Diabetic Patients at MTUTH, February 25 to March 25,2019

\begin{tabular}{|c|c|c|c|c|}
\hline \multirow[t]{2}{*}{ Variable Category } & \multirow[t]{2}{*}{ Appropriateness of Antimedication } & \multicolumn{2}{|c|}{ Glycemic Control } & \multirow[t]{2}{*}{ AOR $(95 \% \mathrm{Cl})$} \\
\hline & & Good & Poor & \\
\hline \multirow[t]{2}{*}{ Dose appropriateness during first clinic visit } & Inappropriate dose & 11 & 59 & $7.698(1.79 I-33.007)^{*}$ \\
\hline & Correct dose & 18 & 22 & 1.0 \\
\hline \multirow[t]{2}{*}{ Dose appropriateness during second clinic visit } & Inappropriate dose & 6 & 54 & $8.083(1.904-34.328)^{*}$ \\
\hline & Correct dose & 23 & 17 & 1.0 \\
\hline \multirow[t]{2}{*}{ Dose appropriateness during third clinic visit } & Inappropriate dose & 7 & 52 & $4.338(1.090-17.172)^{*}$ \\
\hline & Correct dose & 22 & 19 & 1.0 \\
\hline \multirow[t]{3}{*}{ Medication adherence level } & High & 7 & 2 & 1.0 \\
\hline & Medium & 14 & 34 & $3.074(0.382-24.593)$ \\
\hline & Low & 8 & 35 & $11.770(1.383-99.334)^{*}$ \\
\hline
\end{tabular}

Notes: $P$ value $<0.05$ was considered statistically significant. *Statistically significant.

Abbreviation: AOR, adjusted odds ratio. 
Table 5 Predictors of Complications Among Ambulatory Diabetic Patients at MTUTH, February 25 to March 25, 2019

\begin{tabular}{|c|c|c|c|c|c|}
\hline \multicolumn{2}{|l|}{ Variable Category } & \multicolumn{2}{|c|}{ Complication } & \multicolumn{2}{|l|}{ Multivariable Analysis } \\
\hline & & \multirow{2}{*}{$\begin{array}{l}\text { No } \\
11 \\
6 \\
17 \\
7\end{array}$} & \multirow{2}{*}{$\begin{array}{l}\text { Yes } \\
5 \\
10 \\
39 \\
5\end{array}$} & \multirow{2}{*}{$\begin{array}{l}\text { COR(95\%Cl) } \\
1.0 \\
3.667(0.849-15.844) \\
5.047(1.519-16.777)^{*} \\
1.57 \mid(0.330-7.48 I)\end{array}$} & \multirow{2}{*}{$\begin{array}{l}\text { AOR }(95 \% \mathrm{CI}) \\
1.0 \\
0.194(0.024-1.448) \\
0.295(0.028-2.786) \\
0.362(0.036-3.645)\end{array}$} \\
\hline Age & $\begin{array}{l}<30 \\
30-44 \\
45-64 \\
\geq 65\end{array}$ & & & & \\
\hline Type of DM & $\begin{array}{l}\text { Type } 1 \\
\text { Type } 2\end{array}$ & $\begin{array}{l}13 \\
28\end{array}$ & $\begin{array}{l}11 \\
48\end{array}$ & $\begin{array}{l}0.496(0.195-1.249) \\
1.0\end{array}$ & $\begin{array}{l}0.340(0.055-2.11 \mathrm{I}) \\
1.0\end{array}$ \\
\hline Duration of diabetes (years) & $\begin{array}{l}\leq 1 \\
2-5 \\
>5\end{array}$ & $\begin{array}{l}15 \\
20 \\
6\end{array}$ & $\begin{array}{l}17 \\
26 \\
16\end{array}$ & $\begin{array}{l}\text { I.0 } \\
\text { I.I47(0.463-2.840) } \\
2.353(0.732-7.560)\end{array}$ & $\begin{array}{l}1.0 \\
0.983(0.355-2.648) \\
0.513(0.138-1.879)\end{array}$ \\
\hline Comorbidity & $\begin{array}{l}\text { Yes } \\
\text { No }\end{array}$ & $\begin{array}{l}11 \\
30\end{array}$ & $\begin{array}{l}29 \\
30\end{array}$ & $\begin{array}{l}2.636(1.117-6.224)^{*} \\
1.0\end{array}$ & $\begin{array}{l}0.503(0.195-1.314) \\
1.0\end{array}$ \\
\hline Glycemic control & $\begin{array}{l}\text { Good } \\
\text { Poor }\end{array}$ & $\begin{array}{l}11 \\
30\end{array}$ & $\begin{array}{l}18 \\
41\end{array}$ & $\begin{array}{l}1.197(0.494-2.903) \\
1.0\end{array}$ & $\begin{array}{l}1.296(0.134-12.553) \\
1.0\end{array}$ \\
\hline
\end{tabular}

Note: *Statistically significant.

to this discrepancy. In our set up, patients are often given care by general practitioners and nurses. It is afact that the most beneficial approach in preventing complications of diabetes is optimal treatment of hyperglycemia. Apart from that, the discrepancy might be attributed to the differences in the study settings. Conversely, our finding is comparable with the report in Jimma University Specialized Hospital ${ }^{10}$ where $52.5 \%$ of diabetic patients had one or more chronic complication.

\section{Limitation of the Study}

The main limitation of this study was the use of FBG in place of HbAlc to determine the glycemic status. In addition, the cross-sectional nature of the study and the small sample size to oversimplify the findings to the general population.

\section{Conclusions}

The prevalence of poor glycemic control and DM complications was noticeably high among diabetes patients. Low medication adherence level and inappropriate doses in the first, second, and third clinic visits were found to be independent predictors of poor glycemic control among diabetic patients. None of the variables were significantly associated with the development of diabetic complications.

\section{Abbreviations}

DM, diabetes mellitus; FBG, fasting blood glucose; HbA1C, glycated hemoglobin; IDF, International Diabetes Federation;
MMAS, Morisky Medication Adherence Scale; SNNPR, Southern Nations Nationalities and Peoples Region.

\section{Data Sharing Statement}

The supporting documents for this study can be available from the corresponding author upon request.

\section{Acknowledgments}

We would like to acknowledge the study participants for their consent and patience during data collection.

\section{Author Contributions}

All authors contributed to data analysis, drafting and revising the article, gave final approval of the version to be published, and agree to be accountable for all aspects of the work.

\section{Disclosure}

The authors declare that they have no competing interests.

\section{References}

1. Association AD. Standards of medical care WT C, editor. Diabetes Care. 2015.

2. Chapter 3 - The global picture. In: Cavan D, da Rocha Fernandes J, Makaroff L, Ogurtsova K, Webber S, editors. IDF Diabetes Atlas . 7th edition. Brussels: International Diabetes Federation; 2015:50-51.

3. WHO. Global Report on Diabetes. WHO Library Cataloguing-inPublication Data; 2016.

4. Mbanya JCN, Motala AA, Sobngwi E, Assah FK, Enoru ST. Diabetes in sub-Saharan Africa. Lancet. 2010;375(9733):2254-2266. doi:10. 1016/S0140-6736(10)60550-8 
5. Del Prato S, Felton AM, Murno N, Nesto R, Zimmet P, Zinman B. Improving glucose management_ten steps to get more patients with type 2 diabetes to glycaemic goal. Int J Clin Pr. 2005;59(11): 1345-1355. doi:10.1111/j.1742-1241.2005.00674.x

6. Su N, Islahudin F, Paraidathathu T, Paraidathathu T. Factors associated with good glycemic control among patients with type 2 diabetes mellitus. J Diabetes Invest. 2014;5(5):563-569. doi:10.1111/ jdi. 12175

7. Kassahun T, Eshetie T, Gesesew H. Factors associated with glycemic control among adult patients with type 2 diabetes mellitus: a cross sectional survey in Ethiopia. BMC Res Notes. 2016;1-6. doi:10.1186/ s13104-016-1896-7

8. Roman SH, Harris MI. Management of diabetes mellitus from a public health perspective. Endocrinol Metab Clin North Am. 1997;26(3):443-474. doi:10.1016/S0889-8529(05)70260-7

9. Ejigu A. Patterns of chronic complications of diabetic patients in Menelik-II hospital, Ethiopia. Ethiop J Health Dev. 2000;14 (1):113-116.

10. Worku D, Hamza L, Woldemichael K. Patterns of diabetic complications at Jimma University specialized Hospital, Southwest Ethiopia. Ethiop J Heal Sci. 2010;20(March).

11. Gopinath B, Sri Sai Prasad M, Jayarama N, Prabhakara K. Study of factors associated with poor glycemic control in type -2 diabetic patients. Glob J Med Public Heal. 2013;2(2):1-5.
12. Abebe N, Kebede T, Addise D. Diabetes in Ethiopia 2000-2016 prevalence and related acute and chronic complications; a systematic review. Afr J Diabetes Med. 2017;25(2):7-12.

13. Feleke Y, Enquselassie F. Cost of hospitalization of diabetic patients admitted at Tikur Anbessa Specialized Hospital, Addis Ababa, Ethiopia. Ethiop Med J. 2007;45(3):275-282.

14. Morisky DE, Green LW, Levine DM. Concurrent and predictive validity of a self-reported measure of medication adherence. Med Care. 1986;24:67-74. doi:10.1097/00005650-198601000-00007

15. Ghazanfari Z, Niknami S, Ghofranipour F, Larijani B, Agha-alinejad H. Determinants of glycemic control in female diabetic patients: a study from Iran. Lipids Health Dis. 2010;9(1):83. doi:10.1186/ 1476-511X-9-83

16. Fasil A, Biadgo B, Abebe M. Glycemic control and diabetes complications among diabetes mellitus patients attending at University of Gondar hospital, Northwest Ethiopia. Diabetes, Metab Syndr Obes Targets Ther. 2019;12:75-83. doi:10.2147/DMSO.S185614

17. Nduati NJ, Simon K, Eva N, Lawrence M. Factors Associated with glycemic control among type 2 diabetes patients attending Mathari National Teaching Hospital, Nairobi Kenya. J Endocrinol Diabetes. 2016;3(6):1-11. doi:10.15226/2374-6890/3/6/00162

Diabetes, Metabolic Syndrome and Obesity: Targets and Therapy

Dovepress

\section{Publish your work in this journal}

Diabetes, Metabolic Syndrome and Obesity: Targets and Therapy is an international, peer-reviewed open-access journal committed to the rapid publication of the latest laboratory and clinical findings in the fields of diabetes, metabolic syndrome and obesity research. Original research, review, case reports, hypothesis formation, expert opinion and commentaries are all considered for publication. The manuscript management system is completely online and includes a very quick and fair peer-review system, which is all easy to use. Visit http://www.dovepress.com/testimonials.php to read real quotes from published authors. 